\title{
Research on Structural Design Optimization Methods for Civil Engineering Buildings
}

\author{
Zhiyuan Li \\ Chongqing Water Resources and Electric Engineering College (China Chongqing 402160)
}

Keywords: Civil engineering; Building structure; Design optimization; Method

\begin{abstract}
Civil engineering architectural structure design has an important influence on the performance of engineering construction. Therefore, this paper mainly focuses on the problems existing in the design of civil engineering building structures from perfecting drawings, optimizing structural design and improving the use of structural design software. The methods of optimizing the building structure are discussed and analyzed in terms of rate and so on to provide guarantee for the quality of civil engineering construction.
\end{abstract}

With the rapid development of China's economy, the process of urbanization in China has accelerated, and the number of civil engineering constructions has increased year by year. People's attention to the quality of construction projects has also increased. As the foundation of civil construction, building structure not only has a great influence on the quality of the project, but also affects the interests and investment of the owner and construction party. Therefore, optimizing civil engineering building structural design can not only improve the profits of owners and constructors, but also can ensure the quality of civil engineering to a certain extent and prolong the service life of civil engineering construction.

\section{Problems on Structural Design}

\section{Problem in Overall Structural Stability of Building}

The study found that most of the civil engineering buildings are mostly high-rise buildings. After studying the construction process and details of the buildings, it is found that high-rise buildings are easily affected by external factors, and their use performance and structural stability are easily disturbed. Therefore, the stability of the building structure is an important quality evaluation index of the actual construction project which is a problem that the construction party needs to take into consideration. The structural stability of the building not only affects the quality of the building structure, but also results in a certain degree of use performance and life expectancy. For example, some designers often design the deformation joint to separate the main building from the auxiliary building. However, due to the insufficient depth of the building's foundation, when the earthquake and other natural disasters occur in the area, the building will experience slippage and even overturning, and such phenomena pose a serious threat to the residents' property and life safety.

\section{Problem in Floor Plane Stiffness}

When designing a building, designers often have problems due to lack of experience in the layout of the structure, and there are problems in the layout which leads to problems in the calculation of the amount of floor deformation used in the building. Under normal circumstances, the design of the building can be used normally. However, once the floor pressure is too large or the load is too heavy, the building structure will not meet the load-bearing requirements with the design safety limit, which will cause problems such as floor deformation and even building collapse. The reason for these problems is mainly due to the pressure caused by the floor being subjected to excessive pressure. Therefore, when the designer conducts the test of the structural rigidity of the building, it is necessary to fully consider and calculate according to the actual situation so as to avoid the occurrence of structural insufficiency.

\section{Problem in Structural Design Safety}

The quality of the architectural structure design is proportional to the probability of an accident occurring in the building structure. Therefore, the design of the building structure is the primary 
issue that designers should pay attention to. In the actual engineering design process, designers often have the arbitrarily increasing the section of the building or increasing the details of the steel structure used in the building. This phenomenon will not only lead to an increase in construction costs, but also will have an impact on the integrity of the building structure, which in turn affects the safety and performance of our country's building structure.

\section{Optimization Measures of Civil Engineering Building Structure}

\section{Completing Architectural Design Drawings}

The architectural structure design drawings are designers' overall planning for the building structure. Before the construction workers need to work with the designers, the drawings of the building structures are lower, and the construction drawings must be strictly followed in the construction. Therefore, the accuracy of architectural design drawings will have a direct impact on construction quality and the performance of the building. If there is a problem with the design drawings, the construction personnel will have problems in accordance with the design drawings, which will affect the construction progress and quality of the project leading to serious losses to the owners and even the serious safety accidents. Therefore, designers must strictly follow the architectural engineering design specifications to carry out the design work, and do not allow the cutting-off of work or the reduction of the workload. In the process of building structure design, it must be strictly in accordance with the design requirements of the building and it stipulates that a comprehensive design of the building structure should be carried out to avoid any problems with the design drawings due to computational problems or missing parts of the design, which will affect the quality of the project and the progress of the project. For the complex structure of the building structure, the staff needs to consider the problem in more detail and take it seriously. That is to say, when designing and drawing the architectural structure drawings, the designer must avoid the appearance of design defects. The design of the drawings is completed after the design. The personnel and design department must check and verify drawings and construction projects to avoid problems. If design problems are found, the design department must modify the design drawings until the problem is resolved before the construction can be completed to ensure the reliability and rigor of the construction design drawings.

\section{Optimization Of Structural Design}

Building structural design is an important part of the design of civil engineering building structures. This is mainly due to the fact that designers must not only ensure the accuracy of the design drawings, but also need to optimize the structure of the construction projects to meet the normal performance and safety performance of the construction projects. When designing, the designer must ensure the following two points: the purpose of the structural design optimization work is to ensure the quality of the project, and the structural engineering structure optimization work is to reduce the construction investment and cost of the owner, and it also helps to save the investor's capital investment and cost input that are optimized for the construction structure to meet the maximization of the profit of the building owner and construction party.

The purpose of optimizing the building structure is mainly to save construction investment costs. However, it is not blindly lowering the investment cost of the building. Designers need to comprehensively consider the design main body when designing the building structure, select the optimal project and then design according to the design. The guidelines and the actual situation of the building are optimized to ensure the rationality and economy of the design proposal. Therefore, during the design process of the building structure, the designers have to have an experience of the actual situation of the building through the appearance of the field and learn from the construction design experience. Then according to the design principles and design requirements and the actual situation of the building to carry out the bearing capacity calculation of the building-related structures, and according to the properties of the building structure and other construction of the use of performance, it should be designed to meet the design requirements of the building structure. For example, when designing a building structure, it is necessary to analyze and study the bearing capacity, load, temperature stress and seismic performance of the building structure. When 
designing the building structure, the designer needs to comprehensively consider the influencing factors of the building structure, and then according to these factors, the architectural structure is designed and selected to ensure that the building structure has excellent load-resistance performance to ensure the safety of the building structure. In the process of load calculation and architectural structure design, designers should fully consider the actual conditions of the building and the actual situation of the geographical location to modify and optimize the design. In the design plan, the path of the structure transmission force should not be too long, and the most convenient method should be used to achieve the transmission of the building structural load forces. When using the building beams, columns and walls for load transmission, the designer should be responsible for the transmission. The distance and the load-resisting capacity of each structure have an overall grasp to ensure that the building's stiffness and safety performance meet the building construction requirements. Therefore, when designing buildings, designers must pick out reasonable optimization objects, and then design and optimize them according to the design criteria. For the relatively weak links in the design structure, the construction needs to be replaced or the carrying capacity of the construction must be increased to optimize and improve the overall quality of the building.

\section{Application Of Structure Design Software}

With the advent of the information age, computer technology and Internet technology have been widely used in people's lives and work. The era of manual drawing has passed. Architects and designers now use computer graphics software to build architectural drawings and the drawing of the renderings has faster drawing speed compared with the manual drawing, and the renderings are clearly visible and with high precision. Through special drawing software, the design personnel can also be present in three-dimensional of the design drawings of the building structure through professional design software. Then based on the design principles and load requirements, the bearing capacity of the beams, columns and load-bearing walls in the building are calculated and verified. Research shows that computer software can simplify the design process to a certain extent, improve the design accuracy, design efficiency and ensure the transparency and visualization of the design process, so that designers can carry out self-inspection on the rationality of the design of the building structure and the responsible person in charge of the design and comprehensive verification and so on. For example, PKPM design software can be used for the design of high-rise buildings, and the software can also be used for three-dimensional simulation. After the designer has calculated the bearing capacity of the main bearing structure, wall, beam and column of the building structure, he uses PKPM software to simulate its bearing capacity in three dimensions to ensure that the designed bearing capacity meets the application requirements. The specific operation sequence is after the designer completes the design of the bearing wall, column and cross beam, the grid structure of the building simple structure model is meshed using the grid division function in the PKPM software, and then the structural force simulation test is performed for the design structure, and the test results are marked with colors according to the size of the bearing capacity, and the interfaces that are susceptible to fatigue and insufficient bearing capacity are modified or added protection measures to ensure the feasibility and reliability of the design. Designers use computer software to design, simulate and modify building structures. This not only speeds up the design of the building structure, but also improves the design accuracy of the drawings and improves the design pass rate of the building designers. In the actual design process, the designers also need to be familiar with the design principles and design standards and thoroughly understand the design requirements, so as to ensure that the designers can effectively achieve the simplification and replacement of the design structure when using software to simulate the three-dimensional structure. And select a reasonable simulation model to ensure the safety and reliability of the building structure, and then to obtain accurate simulation results and simulation values, and improve the design effectiveness of the building structure, accuracy and quality of the building structure. 


\section{Conclusion}

The design of the building structure is very important for civil engineering construction. It not only affects the quality of the project, but also has an important influence on the safety and performance of the building structure. Therefore, when designing the building structure, designers should improve the safety and performance of the building structure on the premise of ensuring the quality of the project to reduce the construction investment of the owner and the construction party.

\section{Reference}

[1] Zhifeng Zhang, Qianzhen Zhang. Discussion on the optimization measures of building structure[J].China Science and Technology Expo, 2017(43): 178-180.

[2] Yushi Zhang. Discussion on structural optimization design and structural measures[J].Product and Quality, 2017(7): 125-126.

[3] Yuqun Dai. Analysis on the problems of structural optimization design[J].City Building, 2017(6): 72. 